\title{
A SUPERVISÃO COMO EXPERIÊNCIA
}

\author{
Vera Regina da Graça Ruschel e Marta Regina de Leão D'Agord \\ Universidade Federal do Rio Grande do Sul, Porto Alegre, Brasil
}

RESUMO: Este artigo, que enfoca a supervisão como experiência, faz parte de uma pesquisa sobre a questão da supervisão psicanalítica de tratamentos numa clínica-escola. Para tal, trabalha-se com conceitos psicanalíticos de Freud e Lacan. Busca-se, também, para fazer contraponto, analisar uma concepção filosófica de experiência com Agamben (2005). Para além das considerações teóricas, o artigo apresenta a discussão de uma sessão de supervisão. Realiza-se uma leitura psicanalítica sobre essa experiência. Enfoca-se a análise sobre a condução da supervisão de um material clínico, a situação de tratamento e a especificidade da memória do analista supervisionando a partir da concepção de Fédida (1991).

PALAVRAS-CHAVE: supervisão psicanalítica; experiência; psicanálise

\section{THE SUPERVISION AS EXPERIENCE}

ABSTRACT: This article, focusing on supervision as experience, is part of a research about the issue of psychoanalytical supervision of treatments in a university clinic. For such, this paper works with psychoanalytical concepts of Freud and Lacan. As a counterpoint, this work searchs, also, an analysis of the philosophical conception of experience with Agamben (2005). Beyond the theoretical approach, this article presents an analysis of a session of supervision. A psychoanalytical approach on this experience is achieved. The analysis is focused on the conduction of the supervision of a clinical material, the situation of treatment and the memory of the supervising analyst from the point of view of Fédida (1991).

KEYWORDS: psychoanalytical supervison; experience; psychoanalysis

Existem portanto certas experiências que não nos pertencem, que não podemos dizer <nossas $>$, mas que, justamente por isso, porque são, precisamente, experiências do inexperenciável, constituem o limite último ao qual pode lançar-se a nossa experiência em sua tensão para a morte.

(Agamben) ${ }^{1}$

A descoberta - prometeica - de Freud foi uma ação desse tipo; sua obra no-lo atesta; mas ela não está menos presente em cada experiência humildemente conduzida por um dos trabalhadores formados em sua escola.

$(\text { Lacan })^{2}$

\section{Introdução}

O leitor atento da obra de Freud perceberá que, seguidamente, ele faz alusão à questão da experiência em relação à estruturação da teoria que estava construindo. Baseando suas descobertas, antes de mais nada, em sua própria experiência tanto a de laboratório quanto a de sua prática clínica, ele se torna um pesquisador exemplar. Um exemplo pode ser constatado no texto sobre as pulsões (1915/2004) onde ele faz uma introdução destacando a importância da descrição dos fenômenos e posterior classificação e correlações possíveis, antes que se tornem conceitos básicos da teoria. Em 1915 elabora o conceito de pulsão, com base em trabalhos bem anteriores como o Projeto para uma Psicologia Científica (1895-1950/1977) e o capitulo VII da Interpretação de Sonhos (1900), o que nos afigura como um crédito a sua própria experiência.

Considerando essa forma exemplar de trabalho procuramos, no presente artigo, refletir desde nossa própria experiência em relação à supervisão psicanalítica de tratamentos. Nessa perspectiva, consideramos que não há transmissão possível sem a experiência, seja a do supervisionando, seja a do supervisor. Assim, em nosso estudo, consideramos também o que escreve Benjamin (1994) quanto ao resgate da narrativa como fio condutor para a transmissão da experiência.

Encontramos essa preocupação com a reflexão desde a experiência também em Lacan e Fédida. Buscamos ainda aportes na leitura filosófica de Agamben, considerando a contribuição de um outro saber sobre a experiência no estabelecimento de contrapontos ao que nos propomos discutir. 


\section{A interface da experiência na psicanálise e na filosofia}

A noção de experiência em psicanálise, desde as primeiras produções freudianas, se vê atravessadas pelo termo Komplikation utilizado por Freud no "Projeto para uma Psicologia Científica" (1895-1950/1977), ao referirse ao que ocorre no interior do sistema nervoso (com as conotações que ele apresenta sobre sistemas de neurônios). Ademais do termo 'complicação' provavelmente referir-se à difícil articulação entre essa descoberta que apontava para uma leitura biológica e comprometida com uma cientificidade positivista, e as cada vez maiores perguntas surgidas desde sua escuta clínica.

No Seminário sobre a Ética, Lacan (1959-1960/1988), corrobora a escolha freudiana do termo "complicação", considerando a complexidade no entendimento da noção de inconsciente a partir de pressupostos aparentemente objetivos. Daí o conselho que nos dá Lacan de metaforizar essa representação de aparelho psíquico trazida por Freud, considerando-o como uma topologia da subjetividade.

O modo freudiano de lidar com conceitos em elaboração pode ser notado em 1923, quando se defronta com a tarefa de conceituar pulsão de vida e pulsão de morte, quando novamente utiliza o vocábulo 'complicação' (Komplikation), referindo que:

(...) imaginamos que Eros, por ocasionar uma combinação de conseqüências cada vez mais amplas das partículas em que a substância viva se acha dispersa, visa a complicar a vida e, ao mesmo tempo, naturalmente a preservá-la. (...) O surgimento da vida seria, então, a causa da continuação da vida e também, ao mesmo tempo, do esforço no sentido da morte. E a própria vida seria um conflito e uma conciliação entre essas duas tendências (Freud, 1923/1976b, pp. 55-56).

A conceitualização da vida como a luta entre tendências contrárias de manutenção e destruição, ajuda a pensar a 'complicação' aludida por Freud. Se transportarmos esta noção para a escuta clínica, podemos imaginar que se refere à trama dos significantes portados por uma fala que pede decodificação, ou mesmo do sintoma, da inibição ou da angústia com que se apresenta o sujeito que vem em busca de uma escuta para o seu sofrimento psíquico.

A vida e a morte enquanto experiência são temas universais abordados ao longo de séculos tanto pela filosofia quanto pela psicanálise. Assim, o que escreve Agamben (2005) sobre o inexperienciável, destacado na epígrafe acima, aproxima-se do que Freud dizia sobre a tensão vida e morte. Agamben (2005), por sua vez, inspira-se em um relato de Montaigne (1553-1592) no qual este aponta para a possibilidade de nos familiarizarmos com a morte se a conhecermos de perto.
Montaigne cita um incidente em que ele e seu cavalo, atropelados por um serviçal em sua montaria, são prostrados por terra numa experiência de quase morte. Momento que, na sua descrição, assemelha-se ao que estamos considerando sobre a oposição das tendências entre a vida e a morte:

Parecia-me que a vida estava suspensa a meus lábios e eu fechava os olhos a fim de ajudá-la a desprender-se de mim, comprazendo-me nesse estado de langor e também em me sentir esvair. Em meu espírito ocorria a sensação vaga da volta de pensar, mal definida ainda, mais suspeitada do que percebida, sensação terna e doce como tudo o que experimentava, não somente isenta de desprazer mas ainda lembrando a quietude que se apodera de nós ao sermos dominados pelo sono (Montaigne, 1962, p.126).

A literatura se faz pródiga em exemplos dessa natureza, em que autores, através da linguagem poética, procuram formas de descrever, de transformar em relato essa experiência máxima do ser humano que é o de defrontar-se com sua própria morte. Parece que só tomando empréstimos à poesia, é possível falar do que, no inconsciente, não encontra representação.

Quase dois séculos depois do que descreve Montaigne, uma experiência semelhante é relatada por Rousseau (1778/1986): numa ocasião em que, atropelado por um grande cão dinamarquês que perseguia uma carruagem, chegou a desfalecer. Escreve ele:

$\mathrm{O}$ estado em que me encontrei naquele momento é demasiado singular para deixar de descrevê-lo aqui. A noite avançava. Vi o céu, algumas estrelas e um pouco de vegetação. Esta primeira sensação foi de um átimo delicioso. Só através dela eu me sentia. Nascia para a vida naquele instante e era como se eu preenchesse com a minha leve existência todos os objetos que percebia. Inteiramente no momento presente, não me lembrava de nada; não tinha nenhuma noção distinta da minha individualidade nem a menor idéia do que me ocorrera; não sabia quem eu era ou onde estivesse; não provava nem dor, nem temor, nem inquietude. Via escorrer o meu sangue como teria visto correr um riacho, sem nem ao menos pensar que este sangue me pertencesse de algum modo. Sentia em todo o meu ser uma calma inebriante, à qual, sempre que a recordo, não encontro nada de comparável em toda a atividade dos prazeres conhecidos (Rousseau, 1778, citado por Agamben, 2005, p. 50).

Chama a atenção em ambos os relatos, o estado experimentado ao despertar: um certo desconhecimento de si, uma certa confusão entre o corpo e os objetos e o estado inebriante de prazer. Quando escreve que talvez o sono seja uma lição da natureza para nos mostrar que “(...) estamos destinados tanto a morrer como a viver", Montaigne (1962, p. 125) aproxima-se do que escreve Freud sobre pulsão de vida e pulsão de morte, tendências que fazem parte da experiência humana, sendo que a 
vida seria um conflito e uma conciliação entre essas duas tendências (Freud 1923/1976b).

Aqui é possível buscar uma articulação com o pensamento de Agamben quando fala sobre a 'tensão para a morte' que ele lê no relato das experiências de Montaigne ("a quietude que se apodera de nós ao sermos dominados pelo sono") e de Rousseau ("nada de comparável em toda a atividade dos prazeres conhecidos"). Bem como no que escreve Freud no seu estudo sobre o princípio de prazer, quando se refere à tendência do ser humano de busca de um estado de tensão mínima semelhante à morte.

Entretanto, utilizando o termo "tendência", Freud demonstra não se tratar de algo que sempre ocorra desse modo. Ao contrário, em suas palavras: "O máximo que se pode dizer, portanto, é que existe na mente uma forte tendência no sentido de prazer, embora essa tendência seja contrariada por certas outras forças ou circunstâncias, de maneira que o resultado final talvez nem sempre se mostre em harmonia com a tendência no sentido do prazer" (Freud, 1920/1976a, p. 20).

Tomando um exemplo da literatura, recorremos a Proust quando, em sua obra, No Caminho de Swann, descreve de forma intensa esta luta pelo não adormecer do personagem, pois o sono o separaria de sua mãe. A descrição do autor privilegia justamente este tempo entre a chegada e a partida da mãe do quarto do menino. O tão desejado beijo dela parecia constituir-se na única maneira de aplacar a angústia e proporcionar-lhe o relaxamento necessário à chegada do sono.

Quando subia para me deitar, meu único consolo era que mamãe viria beijar-me na cama. Mas tão pouco durava aquilo, tão depressa descia ela, que, o momento em que a ouvia subir a escada e quando passava pelo corredor de porta dupla, o leve frêmito de seu vestido de jardim, de musselina branca, com pequenos festões de palha trançada, era para mim um momento doloroso. Anunciava aquele que viria depois, em que ela me deixaria, voltando para baixo. Assim, aquela despedida de que tanto gostava chegava eu a desejar que viesse o mais tarde possível, para que se prolongasse o tempo de espera em que mamãe ainda não aparecia (Proust, 1982, p. 13).

A passagem do tempo descrita de modo tão poético, especialmente na expressão: "o tempo de espera em que mamãe ainda não aparecia", lembra a descrição que faz Freud do menininho de um ano e meio que, para suprir a ausência de sua mãe, inventou a brincadeira com o carretel, fazendo-o aparecer e desaparecer acompanhando ambos os gestos com evocações: Fort (ir embora) e $D a$ (ali). Mesmo que a linguagem utilizada pela criança possa parecer ainda rudimentar, ela é portadora de uma inscrição simbólica, denota a forma da qual se vale para suportar a ausência da mãe. Forma de expressão que será lida por Freud num après-coup, valorizando como linguagem a emissão de uma criança que apresenta uma fala ainda não articulada, o que ele chama de infans.

A infância do homem, para Agamben (2005) é a experiência antes da palavra. Ele faz alusão a uma espécie de mito de um sujeito pré-linguístico, onde infância e linguagem remeteriam uma à outra: a infância à origem da linguagem e vice-versa. E, nesta relação, se encontraria o lugar da experiência que "(...) coexiste originalmente com a linguagem, constitui-se (...) na expropriação que a linguagem dela efetua, produzindo a cada vez o homem como sujeito" (Agamben, 2005, p. 59).

Aqui, Agamben traz uma formulação semelhante a de Lacan (1949-1966/1998) em "O estádio do espelho como formador da função do eu", quando chama a atenção para a assunção jubilatória da imagem especular pela criança, momento em que se forja no infans a matriz simbólica do eu que lhe permitirá entrar na dialética da identificação com o outro e, pela linguagem, obter no universal a restituição de sua função de sujeito. A afirmação de Lacan de que é a linguagem que nos restitui nossa função de sujeito é uma indicação de que é preciso falar a um outro e se escutar falando. Portanto, sujeito é aquele que poderá se reconhecer na sua produção linguageira como sujeito do inconsciente. A expressão sujeito do inconsciente caracteriza-se pelo uso do genitivo (do inconsciente), indicando que o inconsciente é o agente da ação e o sujeito é aquele que sofre uma ação do inconsciente. À luz da concepção de experiência em Agamben, podemos interpretar o sujeito do inconsciente como aquele que sofre uma ação do inconsciente, mas, ao se reconhecer nessa produção inconsciente, transforma este ato (um ato falho, por exemplo), em uma experiência.

O inconsciente, enquanto restos de percepções, também se situa antes da palavra. Freud (1915/2006) faz a diferenciação entre Wortvorstellungen e $S a$ chvorstellungen, sendo a primeira a apresentação de palavra e a segunda a apresentação de coisa. Uma representação, para ter acesso ao pré-consciente e à consciência, requer sua apresentação em palavras. Os sonhos, enquanto imagens, também se situam antes da palavra. O que Freud vai propor é que há uma experiência subjetiva, uma outra cena, inconsciente, que prescinde da apresentação de palavra.

É dessa cisão entre uma experiência inconsciente e uma experiência consciente que trata Freud, e não deixa de ser o tema abordado por Agamben. A partir do momento em que o sujeito acede às palavras, haverá uma outra experiência. A palavra permitirá ao sujeito tomar um distanciamento em relação às próprias coisas, assim como a separação da mãe, como no caso do Fort-Da. 
Se, como Agamben (2005) observa, a introdução da idéia de inconsciente instaurou uma crise do conceito moderno de experiência, é porque ocorreu a uma mudança de foco. Ou seja, a experiência até então fundada no sujeito cartesiano, no sujeito consciente, entra em crise quando é preciso considerar uma outra forma de experiência, a experiência relacionada ao sujeito do inconsciente. Daí que, na leitura do autor, o Es no exemplo da queda de Montaigne não é a morte, pois o limite da experiência se inverteu: não mais em direção à morte $\mathrm{e}$ sim à infância. Infância que, conforme aludimos antes, tem relação com o infans freudiano. No que acabamos de discutir, reside uma importante aproximação entre a questão da experiência na leitura psicanalítica e na leitura da filosofia proposta por Agamben.

Lacan, na epígrafe que trouxemos, refere-se à questão de experiência na psicanálise. No texto Função e Campo da Fala e da Linguagem em Psicanálise (1953-1966/1998) destaca o valor da experiência quando está tratando da aproximação da psicanálise com outros saberes, especialmente com a antropologia e com a filosofia, saberes dos quais, segundo ele, a psicanálise só tem a se beneficiar (Lacan, 1953/1998, p. 241). E se não for conotado à experiência seu devido valor, a psicanálise não passará de uma prática preocupada com os efeitos do sentido e suas regras técnicas serão reduzidas a receitas. Nesta fala de Lacan, pode-se ler um crédito especial ao que Freud jamais deixou de considerar, ou seja, a experiência, o fundamento que justifica todo o arcabouço teórico e prático da psicanálise.

Uma destacada contribuição de Lacan à psicanálise refere-se ao estudo do fenômeno da linguagem aportando a ela o estatuto de ferramenta essencial no trabalho do psicanalista. E, em possuindo a linguagem uma materialidade, busca respostas no outro. Então, como nos lembra Lacan, as palavras podem, por exemplo, engravidar a histérica. E sua materialidade, paradoxalmente, fazer-se presente na ausência ou no tropeço, buscando significação na escuta de um outro: $o$ analista em seu fazer.

Quando se refere a cada experiência conduzida pelos trabalhadores formados na escola fundada por Freud, Lacan nos chama a atenção para que a história da construção dessa escola ocorreu pelo trabalho solitário de Freud baseado em sua crença na linguagem. Como sua intervenção no caso do pequeno Hans somente escutando seus pais e na decifração de uma faixa inteira da linguagem do inconsciente no delírio paranóide, baseando-se unicamente no texto deixado por Schreber.

A experiência freudiana, inventando um método de tratamento de escuta do inconsciente através de emissões da linguagem e a releitura lacaniana da psicanálise freudiana, corroborando a mesma causa, aproximam a psicanálise também da lingüística.
A contribuição de Lacan em relação à linguagem compara, por exemplo, a conotação vocálica no jogo do Fort-Da com a descoberta do fonema que permite infinitas possibilidades articulatórias e o trabalho com o símbolo que impõe à ciência uma nova classificação das ciências: as ciências da subjetividade.

\section{Experiência da Supervisão: da Teoria à Prática}

Com o recorte que a seguir apresentaremos, pretendemos discutir algumas questões que dizem respeito à prática da supervisão psicanalítica de tratamentos.

Numa sessão de supervisão, o terapeuta relata ter recebido em tratamento um jovem de 24 anos cujo sintoma se faz sentir na fala através de uma gagueira. É como ele se apresenta. Com uma emissão de palavra precedida de trejeitos de boca e língua, inspirações e expirações, que explica ao terapeuta ser um exercício que aprendeu com a fonoaudióloga. Vem a duas sessões e, na segunda, diz ao terapeuta que seu problema começou aos 8 anos de idade mas que tem vergonha de falar sobre isso. Falta à sessão seguinte. $\mathrm{O}$ terapeuta encontra o paciente, casualmente, no estacionamento da Clínica quando este saía da sessão com a fonoaudióloga. O paciente marcava o atendimento psicoterapêutico e $o$ fonaudiológico no mesmo dia. Diz que não compareceu à sessão porque deseja trocar de terapeuta, sendo que este o convida a vir ao próximo horário agendado. Na sessão de supervisão, o terapeuta mostra-se angustiado com a situação, interrogando-se sobre os motivos da atitude de seu paciente. Consideramos a questão da vergonha mencionada na última sessão. Talvez a referência a algum episódio penoso de sua história que não desejasse enfrentar, isto é, falar sobre isso. No entanto, não deixou de comparecer ao tratamento fonaudiológico, lugar de manipulação do órgão emissor da palavra onde ele faz sintoma. Porque o desejo de trocar de terapeuta? Não sabemos. Na tentativa de explicar o não comparecimento do paciente, o terapeuta levanta a hipótese de que se trate de um "jogo histérico" (sic) na transferência. Isto é, deixar o terapeuta esperando ao não avisar que iria faltar à sessão. Ao atribuir ao paciente um jogo histérico, o terapeuta faz uma interpretação do acting out, interpretação que o ajuda a suportar a angústia do não saber.

Devido a essa situação, o terapeuta marcou uma supervisão, pois era preciso colocar em palavras, falar, tentar elaborar o que se passava na transferência. Mas, para isso, era preciso escutar o paciente para além dos sintomas de fala. Era preciso escutar o sujeito que se escondia por trás da escansão gaguejante entre uma sílaba e outra e dos trejeitos bucais durante a fala. Considerar que o paciente não se reduz ao modo como se apresen- 
tara na primeira sessão de psicoterapia: "um caso grave de gagueira diagnosticado pela fonoaudióloga". Se esse sujeito retornar ao tratamento psicológico, é porque estará em processo a desconstrução da identificação ao adjetivo gago na sua representação subjetiva, a qual faz com que, no momento, prefira o tratamento que mantém o órgão emissor da palavra num lugar de erotização.

Como o recorte nos aponta, o não saber que se instala na sessão de supervisão é o verdadeiro mote ao trabalho. Pois, como nos lembra Lacan (1953/1998), o que dá sentido ao discurso do sujeito é uma pontuação feliz, a interrupção de uma sessão obedecendo à trama do discurso, uma escansão com valor de uma intervenção.

A supervisão vem promover essa elaboração por parte do terapeuta e isso faz com que a experiência se torne tão instrutiva para o supervisor quanto para aquele que procura supervisão. Fédida (1991a) considera que falar de um tratamento a um terceiro provoca modificações sobre a economia do silêncio e da fala do analista no tratamento.

Em "A Construção do Caso", Fédida (1991b) exemplifica um recorte de supervisão que ajuda a pensar dois momentos importantes de uma escuta analítica: aquele em que o analista assume uma postura detetivesca em relação ao material que escuta de seu analisante $\mathrm{e}$, em contraste, quando faz uso de escuta equiflutuante, auxiliando o analisante a exercer a livre associação. Trata-se do caso de um paciente masculino, com cerca de quarenta e três anos, levado à supervisão pela dificuldade que a analista vinha encontrando em escutá-lo devido ao sono que o acometia durante as sessões. Numa sessão de supervisão, a analista traz algo novo no relato do paciente: este refere uma cena de quando tinha mais ou menos dois anos em que observa uma discussão entre os pais no quarto destes, sendo que o que se destaca aí é a janela aberta para o jardim. Ao relato desta, o paciente cai em sono, mas, incentivado pela analista a continuar, lembra de uma cruz sobre uma tumba. Diz que não era no cemitério, pois este ficava mais longe e, portanto, não seria possível vê-lo desde tal janela. Sobre o cemitério, lembra de ter ido algumas vezes lá com seus pais por volta dos doze anos. Depois disso, volta a dormir em sessão. A analista, então, interpreta que alguém muito próximo do paciente deveria ter sido enterrado no jardim e, posteriormente, levado para o cemitério. Esta fala da analista desperta o paciente que lhe responde ser impossível o que ela havia sugerido.

$\mathrm{Na}$ sessão de supervisão, analista e supervisor associam a cruz a outros momentos da história do paciente: a cruz formada por duas barras de ferro que ficavam sobre o poço do jardim da casa do avô; cruz na agenda dele, marcando o número de seu telefone e o nome de sua mulher no momento de sua separação; cruz sobre um mapa, feita por uma amiga, em uma viagem recente do paciente, para indicar-lhe a localização de sua casa. Enfim, as associações surgidas durante a sessão de supervisão, inicialmente, incitadas pelo supervisor, possibilitaram que a analista deslocasse o foco de sua escuta da cruz como fato para considerá-la como significante. Ou seja, a situação de supervisão convoca, na analista, uma memória de sua escuta que reporta à relação transferencial (dela com o analista supervisor e dela com seu paciente).

Eis aqui um ponto crucial da situação de supervisão, considerando que a memória, neste caso, não se refere à reprodução de falas do analisante, nem a recortes de sessões que valorizam a observação, a atenção eletiva, a memorização ou a síntese recapitulativa. A memória em questão tem a ver com o inconsciente, não só do analisante, mas, na situação de supervisão psicanalítica, também com o inconsciente do analista que, por meio de uma escuta terceira (do supervisor) pode acessar seus equívocos de escuta, sua surdez, suas precipitações, etc. Quanto a este aspecto, Fédida (1991a), lembra da diferença entre a memória narrativa, que se importa com o relato de sessões, e, de outro modo, a memória do infantil no analista. A escuta psicanalítica privilegia a memória resultante da atenção equiflutuante do analista, isto é, a memória inconsciente. Assim, a escuta do analista não pode ser seletiva, comprometida com o registro de recortes que seriam interessantes levar à supervisão.

Retornando à questão antes levantada sobre a postura detetivesca da supervisionanda de Fédida, ao comunicar ao paciente que a cruz deveria ser a do túmulo de uma pessoa próxima dele, interpreta factualmente a lembrança de uma cruz que ainda não havia entrado na cadeia associativa dele. Ao passo que, quando escuta os ruídos de seu sono (o engurgitamento dos líquidos do corpo ao fungar e engolir enquanto dormia em sessão) e os pontua, abre margem para que ele associe livremente e possa seguir falando. Surge então, no discurso dele, a palavra "invaginação", evocando seu desejo de voltarse para dentro de seu próprio corpo, o que foi escutado pela analista como um retorno autonutritivo. Conforme Fédida (1991b), assim que a compulsão auto-erótica (autística) ao sono tornou-se transformável em formas imagináveis, lugares psíquicos começaram a existir. Como "lugares psíquicos" podemos pensar partes de frases que escutamos de pacientes do tipo: "isto me lembra (...)"; "é como se (...)"; "me dá a impressão de ser tal coisa (...)", indicativas de que algo se produz como possibilidade de acesso a conteúdos inconscientes, pois o lugar do psíquico, diz Fédida (1991b), é o lugar de constituição de qualquer acontecimento.

Aqui se pode pensar sobre os efeitos de uma escuta amparada na atenção equiflutuante, que não está comprometida nem com a linearidade, nem com a lógica do discurso. No caso acima, a palavra "cruz", 
remetendo ao túmulo e ao jardim, constitui-se como um significante que só pode buscar alguma significação a partir das associações do paciente amparadas em sua memória inconsciente.

Ao considerar - numa sessão de supervisão - que o túmulo referido pelo paciente poderia ser o de uma irmã mais velha deste, Fédida (1991b) destaca que se trata de uma fantasia partilhada entre supervisor e supervisionanda que surge no lugar do não-dito do paciente, o que não autorizaria a analista a formar uma interpretação comunicável a ele. Até porque, em suas considerações, Fédida (1991b) refere que a cruz, além de um elemento que poderia ser um auxiliar na direção da escuta da analista, também foi o indicador de uma "formação focal cega" (1991b, p. 226), dificultando, a ela, as condições de sua escuta e de sua memória.

Tomando-se estes dois momentos da experiência relatada por Fédida, pode-se pensar que, quando a analista sugere ao paciente a possibilidade da cruz no jardim ser do túmulo de uma pessoa próxima dele, está colocando uma leitura imaginária, a serviço de uma busca de confirmação. Ao passo que, quando se vale do discurso do paciente (palavra "invaginação" e a pontuação sobre os ruídos produzidos por seu corpo), valoriza a escuta equiflutuante e abre a possibilidade para a livre associação.

O caso analisado acima permite pensar a ética na situação de supervisão psicanalítica que, por valer-se eminentemente do discurso (tanto do paciente quanto do analista sobre o paciente) considera que este não pode ser o de uma ideologia de poder. Existe, pois, nesta situação, uma especificidade que é a da palavra destinada a um terceiro, cujo exercício deste lugar produzirá efeitos na prática do supervisionando. Efeitos esses que dizem da relação transferencial estabelecida entre o analista supervisionando e o supervisor.

Fédida (1991a) lembra que a situação de supervisão é o lugar privilegiado onde é possível a elaboração de uma teoria psicanalítica do trabalho psíquico do analista, de sua psicopatologia e de sua "contratransferência" (1991a, p. 172). Isto nos permite abordar a supervisão com os mesmos parâmetros com que se trabalha metapsicologicamente, isto é, um espaço atravessado pelas condições de uma psicanálise que não é um tratamento, mas que implica também a este. Pois, a escuta do analista não está isenta dos atravessamentos de suas próprias formações inconscientes. E, de modo semelhante, quando fala de seu paciente a um outro, na forma apontada por Lacan (1953/1998) "de um filtro, ou então de um refrator do discurso do sujeito" apresentando ao supervisor "uma estereografia que já destaca os três ou quatro registros em que ele pode ler a divisão constituída por esse discurso" (Lacan, 1953/1998, p. 254). A forma de registro faz-nos pensar justamente de que modo funciona a seleção do material clínico a ser levado em supervisão. A tarefa de contar sobre o que escutou de seu paciente pode estar atravessada por diversas formas possíveis: contar uma após outra as sessões semanais, tentando reconstituir com a máxima fidelidade o discurso do paciente; trazendo anotações tomadas após as sessões ou simplesmente associando livremente sobre a experiência para que possam surgir os lapsos, os esquecimentos, os equívocos, as perguntas. Em nossa leitura, reside neste último, um exercício eficaz deste modo sui generis da experiência psicanalítica constituído pela supervisão de tratamentos. Acreditando, sobretudo, nas possibilidades da atenção difusa ou equiflutuante $\mathrm{e}$ valorizando a escuta do significante, tanto do que pode surgir do discurso do paciente quanto do que pode ser produzido pelo analista durante a sessão de supervisão.

\section{Conclusão}

A escuta clínica não é um mero registro das falas, como o é a escrita de um técnico que faz estereografia. Pelo contrário, na escuta equiflutuante, trata-se de se deixar atravessar pela "memória do infantil" (Fédida, 1991a).

A implicação do clínico na escuta psicanalítica vai ao encontro da concepção de elaboração simbólica própria da experiência, tal como Benjamin (1994) a define em contraponto à técnica. É dessa experiência de escuta que se trata na situação de supervisão psicanalítica de tratamentos. Assim, essa não é um lugar de relatos de fatos, mas de fala desde uma experiência. Experiência esta em que tanto a escuta do supervisor quanto a do supervisionando, supõem um saber no analisante, uma elaboração simbólica do vivido.

A escuta psicanalítica, ao não privilegiar a fala como relato, descola-a dos fatos e a reporta ao saber que não se sabe, o saber inconsciente. Deste modo, pode-se pensar na supervisão como momento de transmissão que, na psicanálise, é um efeito da transferência e da suposição de saber. E ambas são condições que apontam para a produção simbólica a partir da fala.

\section{Notas}

1 Agamben, G. (2005) A Queda de Montaigne e o Inconsciente. In Infância e história: destruição da experiência e origem da história, p. 50.

2 Lacan, J. (1953/1998). Escritos, p. 243.

\section{Referências Bibliográficas}

Agamben, G. (2005). Infância e história: destruição da experiência e origem da história. Belo Horizonte: Editora UFMG.

Benjamin, W. (1994). Experiência e pobreza. In Magia e técnica, arte e politica: ensaios sobre literatura e história da cultura (pp. 114-119). São Paulo: Brasiliense. 
Fédida, P. (1991a). A Construção. Introdução a uma questão da memória na supervisão. In Nome, Figura e Memória - a linguagem na situação psicanalítica (pp. 171-181). São Paulo: Escuta.

Fédida, P. (1991b). A Construção do Caso. In Nome, Figura e Memória - a linguagem na situação psicanalítica (pp. 215-236). São Paulo: Escuta.

Freud, S. (1976a). Além do princípio de prazer. In Edição Standard brasileira das obras psicológicas completas de Sigmund Freud. (Vol. XVIII, pp. 13-85). Rio de Janeiro: Imago. (Trabalho original publicado em 1920).

Freud, S. (1976b). O Ego e o Id. In Edição Standard brasileira das obras psicológicas completas de Sigmund Freud. (Vol. XIX, pp. 13-83). Rio de Janeiro: Imago. (Trabalho original publicado em 1923).

Freud, S. (1977) Projeto para uma psicologia científica. In Edição Standard brasileira das obras psicológicas completas de Sigmund Freud (Vol. I, pp. 395-506). Rio de Janeiro: Imago. (Trabalho original publicado em 1815-1950).

Freud, S. (2004). Pulsões e destinos da pulsão. In Obras Psicológicas de Sigmund Freud. Escritos sobre a Psicologia do Inconsciente (Vol. I, pp. 133-173). Rio de Janeiro: Imago. (Trabalho original publicado em 1915).

Freud, S. (2006). O inconsciente. In Obras Psicológicas de Sigmund Freud. Escritos sobre a Psicologia do Inconsciente. (Vol. II, pp. 13-74). Rio de Janeiro: Imago. (Trabalho original publicado em 1915).

Lacan, J. (1988). O seminário, Livro 7: A ética da psicanálise. Rio de Janeiro: Jorge Zahar. (Trabalho original publicado em 1959-1960).

Lacan, J. (1998a). Função e campo da fala e da linguagem em psicanálise. In Escritos (pp.238-324). Rio de Janeiro: Jorge Zahar. (Trabalho original publicado em 1953).
Lacan, J. (1998b). O estádio do espelho como formador da função do eu. In Escritos (pp. 97-103). Rio de Janeiro: Jorge Zahar. (Trabalho original publicado em 1949-1966).

Montaigne, M. (1962). Ensaios. Porto Alegre: Globo.

Proust, M. (1982). No Caminho de Swann. São Paulo: Vitor Civita Editor.

Rousseau, J. -J. (1778/1986). Os devaneios do caminhante solitário. 2.ed. Brasília: Ed. UnB.

Vera Regina da Graça Ruschel é Psicóloga, membro da equipe técnica da Clínica de Atendimento Psicológico

da UFRGS, Mestre em Psicologia Social e Institucional,

UFRGS. Endereço: Clínica de Atendimento Psicológico da UFRGS, Av. Protásio Alves, 297. CEP 90410-000, $3^{\circ}$ andar, Porto Alegre/RS. Email: vrgr@terra.com.br

Marta Regina de Leão D'Agord é Psicóloga, Mestre em Filosofia, Doutora em Psicologia, Professora do Departamento de Psicanálise e Psicopatologia do Instituto de Psicologia, Universidade Federal do Rio Grande do Sul (UFRGS). Pesquisadora junto ao Programa de Psicologia Social e Institucional do Instituto de Psicologia, UFRGS. Endereço: UFRGS, Instituto de Psicologia, Rua Ramiro Barcelos, 2600. CEP 90035-003, Porto Alegre/RS. Email: mdagord@terra.com.br

\section{A supervisão como experiência}

Vera Regina da Graça Ruschel e Marta Regina de Leão D’Agord

Recebido em: 06/12/2007

Aceito em: 03/10/2008 